\title{
ANSERJ
}

Vol. 10 , No. 2

Autumn / Automne 2019

pp. $55-76$

Canadian Journal of Nonprofit and Social Economy Research

Revue canadienne de recherche sur les OBSL et l'économie sociale

\section{Funding Nonprofit Radio Technology Initiatives in Canada}

\author{
Geneviève A. Bonin-Labelle \& Jean-Simon Demers \\ University of Ottawa
}

\begin{abstract}
Media organizations worldwide are struggling to find sustainable financial models since the arrival of the internet. Nonprofit radio is no different. Using a thematic analysis of 62 Canadian nonprofit stations' financial statements from 2012-2015, this study examines the impact of the Community Radio Fund of Canada's Radiometers' grant competition. Although results show a small financial gain for those who received funding, the study fails to determine the value of relying on such a grant for long-term technological sustainability. This study also shows the classic income effect by demonstrating how stations continued spending on technology whether they received grants or not. Recommendations include creating a matching fund program to encourage stations to find alternative sources of income to sustain their projects and increase accountability.
\end{abstract}

\section{RÉSUMÉ}

Les organisations de médias à travers le monde luttent pour trouver des modèles financiers durables depuis l'arrivée d'internet. La radio à but non lucratif n'y échappe pas non plus. En effectuant une analyse thématique des états financiers de 62 stations canadiennes à but non lucratif de 2012-2015, cette étude examine l'impact de la compétition Radiomètres du Fonds canadien de la radio communautaire. Malgré le fait que les résultats démontrent un petit gain financier pour ceux ayant reçu du financement, l'étude ne parvient pas à démontrer la valeur de ce type de subvention pour une durabilité technologique à long terme. Cette étude valide aussi l'effet de revenu classique en démontrant que les stations continuent à effectuer des dépenses en technologie, peu importe s'ils ont obtenu ou non une subvention. Les recommandations comprennent la création d'un programme de fonds de contrepartie, afin d'encourager les stations à trouver des sources alternatives de revenus afin de soutenir leurs projets et d'accroître l'imputabilité.

Keywords / Mots clés Nonprofit radio; Technology; Funding; Canada / Radio à but non lucratif; Technologie; Financement; Canada 


\section{Bonin-Labelle \& Demers (2019)}

\section{INTRODUCTION}

In Canada, radio broadcasting represents 10.5 percent of overall broadcasting revenue $(40.1 \%$ for television and $49.4 \%$ for cable, satellite, and internet protocol television [IPTV], otherwise known as broadcast distribution undertakings, or BDUs, in Canada) and it is divided into three types of stations: commercial radio stations, stations operated by the public broadcaster, and other non-commercial stations (CRTC, 2018). These non-commercial stations include community, campus, Indigenous, and religious stations. For the most part, they are nonprofit radio stations funded by the community through local adverting (84\%, as opposed to $65 \%$ for commercial stations), fundraising, and government grants (CRTC, 2018). In 2017, these stations generated $\$ 71.8$ million in revenue (CRTC, 2018) and accounted for 25.4 percent of the radio industry (CRTC, 2017a). Despite losing seven stations from 2013 to 2017, the sector has seen modest financial growth, which is impressive given radio listenership has been slowly declining for more than a decade.

While community radio stations, in particular, are "inexpensive and easy to build and operate" (Salter \& Odartey-Wellington, 2008, p. 286), increasing costs, competition, and constant pressure to keep up with technological developments present continuous challenges. In a recent Canadian Radio-television and Telecommunications Commission (CRTC) ${ }^{1}$ hearing, some groups (CHUO FM was provided as an example, but, unfortunately, not all parties were identified in the decision) even suggested that instructional stations that are part of the sector should simply "migrate to Internet broadcasting" (CRTC, 2010, par. 23). Despite its hardships, however, the sector is known for its creativity, including "develop[ing] technologies to serve identifiable needs rather than market gaps" (Rennie, 2007, p. 25). In other words, stations tend to cater to the needs of their specific communities rather than create content or services that correspond to communities identified through market surveys, such as targeting a particular age group that is perceived to be more susceptible to listening to radio. For example, a radio archive may be created to protect the cultural heritage of an Indigenous community rather than spending money on advertising. Funds may also serve to create spoken-word content from the LBGTQ2+ community that can be shared throughout a network instead of sponsoring a pop music festival geared to 15-year-olds, which would be akin to commercial radio practices.

The CRTC itself has even determined that community radio stations offer Canadian listenership a choice because they have a mandate to reflect those they serve and also to distinguish themselves from commercial stations (Salter \& OdarteyWellington, 2008). In debates leading up to the current Campus and Community Radio Policy (CRTC, 2010), it became clear that the internet is seen as a useful supplement and not a replacement for traditional community radio broadcasting (Fauteux, 2015). A community station offers more than just on-air broadcasting. It is a meeting place and a platform for marketing local talent. This conclusion allowed decisions about the sector to be brought back to the important issue of finding ways to maintain its sustainability and continue to improve its technological development. As such, this study sheds light on how well stations that have received funding for projects with technological implications through the Community Radio Fund of Canada (CRFC) are performing in relation to those that did not.

The CRFC is an independent nonprofit organization created in 2007 through a partnership between the three largest community radio associations in the country. ${ }^{2}$ It was seen as a solution to help "build and improve campus and community radio for all Canadians" (CRFC, n.d.-a). The organization truly blossomed when the CRTC determined that the CRFC was approved to manage over \$1.5 million emerging from the unprecedented merger of media giants Astral Media Inc. and Standard Radio (CRTC, 2007). This $\$ 1.8$ billion deal created the largest radio broadcasting company in the country (CBC, 2007). In 2010, the CRTC (2010) went a step further in suggesting that a mandatory 15 percent of annual Canadian content development ${ }^{3}$ contributions be made to the CRFC. This suggestion was implemented as an amendment to the Radio Regulations, 1986 on 31 July, 2013 (CRTC, 2013). Since its inception, the CRFC (2018) has distributed several million dollars to campus and community stations in the country, including over $\$ 12$ million through its Radiometers program alone. 


\section{Bonin-Labelle \& Demers (2019)}

The CRFC has run four distinct programs since its launch. The Radio Talent Development Program ran from 2009 to 2014 and served to develop "innovative local interest programing by: a) producing local-interest content in the area of spoken word, and b) providing training, mentoring, and-or education to those producing this content" (CFRC, n.d.-b). It provided \$461,539 for 65 different projects. The Youth Internship Program also ran from 2009 to 2014 and awarded $\$ 494,879$ for 62 internship-related projects (CRFC, n.d.-c). Youth on Air! was launched in 2015 as a pilot project. The goal of this program is to offer training, mentoring, and education projects (CRFC, n.d.-d). So far, $\$ 419,303$ has been awarded to 44 different projects in its two first rounds (CRFC, n.d.-d). Finally, there is Radiometers, which is the program most relevant to this article. Since September 2012, it has awarded over $\$ 12$ million for 360 unique projects (CRFC, 2018). This "outcome-based approach" program serves to fund projects from stations that hold a valid campus or community radio licence. The CRFC and its funders must be able to measure the short-, medium-, and long-term success of the projects using a series of metrics (CRFC, 2018a). Individual stations put forth projects with the approval of their board of directors. The CRFC ultimately measures the success of the projects. No study, to our knowledge, has yet examined the CRFC's management of this process as well as how stations have performed when awarded different grants.

The CRFC's (n.d.) programs are built around four priority areas: local community news and access, community music and expression, emerging distribution technologies, and sustainability and capacity building. This article closely analyzes this last priority.

Unlike other sectors such as health and education, the media industry does not have a systematic evaluation practice as part of its day-to-day activities. In the media sector, particularly regarding radio, evaluation differs from how it is considered in other disciplines. Using the term itself is somewhat off-putting, as the assessment exercises are limited to reports by consultants in the field providing expert advice on their perception of the success of a program or policy loosely using methodology that is often not documented and cannot be replicated (Bonin, 2010). Notwithstanding government reports on the state of the broadcasting sector (see, for example, the Standing Committee on Canadian Heritage, 2003, and yearly CRTC monitoring reports academic research in this particular area of the community sector has been scarce (Bonin, 2012), which explains why many questions about evaluation and its role in the sector still remain unanswered, including issues of financial accountability. However, the purpose of this article is not so much to examine the historical nature of evaluation in the sector but, using an evaluation-inspired methodology, to examine grant utilization as a justifiable option for funding technological initiatives over time. With this in mind, it is not unreasonable to wonder what the impact of a young organization such as the CRFC has been in achieving its specific program objectives and to what extent it offers hope for a more sustainable future. Consequently, this article seeks to answer the following two preparatory questions as they lay the initial groundwork for ongoing research on this particular aspect of community radio funding and the development of evaluation tools to study this sector of broadcasting:

- What impact has the CRFC's support for initiatives related to technology had on the financial situation of stations that have benefited from grants in comparison to those that have not?

- How valuable is the grant funding from the CRFC for sustaining individual stations and their technological plans?

The following pages present a detailed description of the sector and funding, as well as an overview of existing research in the field. The methodology for this study follows, which is inspired by formal evaluation processes (or standards), including the sampling process, a breakdown of the information gathered, and the way it was aggregated. A presentation of the results comes next, followed by the discussion and conclusion, which focus on the ways Canadian nonprofit radio stations can improve in the face of an ever-changing broadcasting landscape.

\section{OVERVIEW OF THE NONPROFIT RADIO SECTOR IN CANADA}

According to the CRTC's (2018) annual monitoring report, Canada's radio industry comprises 712 commercial stations 


\section{Bonin-Labelle \& Demers (2019)}

(591 FM stations) generating $\$ 1.5$ billion in revenue; 67 public radio stations (53 FM stations) operated by the Canadian Broadcasting Corporation (CBC), generating \$295 million in revenue; and 221 non-commercial stations generating $\$ 71.8$ million in revenue. ${ }^{5}$ The non-commercial stations average about $\$ 325,000$ in revenue and are comprised of 48 campus stations: 112 community stations, 32 Indigenous stations, and 29 religious stations (CRTC, 2018).

Most Canadian studies related to this sector have generally been interested in "community and campus stations." However, the most recent CRTC (2010) policy (Broadcasting Regulatory Policy CRTC 2010-499) divided stations into two distinct categories. Stations on university and college campuses ${ }^{7}$ are called "campus stations." These are different from so-called "instructional stations," which are often in a closed circuit or are used strictly as training facilities to teach future radio professionals. In 2010, the CRTC (2010) decided it would no longer provide licences for instructional stations but would allow those running the stations the opportunity to apply as a formal "campus station" according to their needs.

"Community stations" are those situated outside educational facilities that serve the communities in which they are established (CRTC, 2010). Prior to 2010, stations were considered to be campus-community stations because the employees and volunteers of these stations were not only from educational institutions, but also from the community at large. This is most likely due to their higher wattage which allowed them to reach people outside campus boundaries and to participate in off campus activities. Although the terms have changed, the realities of these stations have not. For example, several campus stations are still run by various people in the community, not only by students. Some of these stations rent space on campuses.

These policy changes were made to better distinguish station licences, yet the term "nonprofit stations" is used in this study, as it is felt to be more inclusive of both community and campus stations, as well as of all other stations that have a nonprofit status. ${ }^{8}$ This is important as it includes some stations the CRTC (1990) calls "native" or "aboriginal" stations, but have a nonprofit status, and therefore, similar financial obligations and governance structures. This study refers to them as "Indigenous or First Nations stations" as this is the current socially acceptable terminology. "Indigenous stations" is also the term the CRTC used in its last monitoring report. Although the Indigenous stations are not eligible for the CRFC's grants, it is important to note their existence as they were part of the initial population.

\section{FUNDING OF CANADIAN NONPROFIT RADIO}

The main difference among stations in the nonprofit sector relates to their financial profile. Campus stations often have a steady income in the form of levies collected from fees paid by students for ancillary services provided on campus. Some exceptions remain, for example, station CJMQ out of Sherbrooke, Québec, holds a community licence while operating from the Bishop University campus. Its main funding comes from the Québec government (Culture et communications Québec, 2016). Community stations, on the other hand, do not benefit from this type of funding. Some universities allow exemptions of these payments, but most students do not avail themselves of this option. It may be that they are not informed of this possibility, perhaps they simply feel their station is part of a healthy campus life or, more likely, that the process to opt out is cumbersome. In the fall of 2019, however, campus stations in Ontario will likely take quite a hit in this respect, as the provincial government's proposed new policy framework (Ministry of Training, Colleges and Universities, 2019) allows students to opt out of certain student services at the time of registration. This new policy was proposed as a solution to reduce tuition fees without considering consequences. This decision will have a detrimental impact on campus station revenues throughout the province, democracy as a whole, and may even lead to the closure of stations.

There are other particularities when it comes to funding. Community stations in Québec (excluding campus and instructional and Indigenous stations) receive a basic annual funding amount from the provincial government that ranges from $\$ 39,665$ to $\$ 60,000$, in addition to another amount that is determined based on their production (Culture et communication 


\section{Bonin-Labelle \& Demers (2019)}

Québec, 2016). There are many Indigenous radio stations in Canada that operate on land belonging to First Nations, Inuit, and Metis people. These stations are exempt from the current native radio broadcasting policy (CRTC, 1998). Other licenced nonprofit stations that serve Indigenous communities throughout Canada receive federal funding, except those below the Hamelin line. ${ }^{9}$ However, since the early 1990s, this funding has drastically diminished, leaving Indigenous community stations to find alternative ways to support themselves while continuing to produce content and serve their communities.

Since the majority of community stations across the country are not privy to steady financial support, it is not surprising that people working in this sector are consistently trying to improve their collective situation by finding more sustainable funding options. The majority of stations take part in advertising and fundraising activities, but the recent establishment of the CRFC has provided new options for station development. The effectiveness of this funding source as a sustainable solution for the sector is still up for debate. As explained in the next section, this situation is not unique to Canada.

\section{RESEARCH ON NONPROFIT RADIO}

According to Gretchen King (2017), there are various definitions and documented histories of community radio, which are as unique as the contexts it has evolved in. To describe its history, King (2017) maintains that researchers start in different places from the evolution of early broadcasting by Indigenous peoples to the development of broadcasting technologies and from the creation of regulation and policies to what she suggests is a more encompassing view involving a review of community radio practises from around the world. Although macro research in philanthropy or nonprofit management may have provided some general information on financial management, sustainability, or the evaluation of nonprofits, these were voluntarily put aside due to the specificities of the subject at hand, the federal jurisdiction of radio in Canada, and the fact that no other article has examined the scope of research within the sector itself to determine the availability of information on nonprofit finances among the variety of themes and topics. This article, therefore, highlights and acknowledges these research themes on nonprofit radio, but focuses on the empirical work that has been conducted about this sector worldwide, particularly in the form of case studies, as it relates specifically to funding, which is most relevant in this context. In other words, this article is not only shaped by a theoretical framework of combined studies on community media but also builds a new lens through which to examine community radio funding.

Despite possible links to financial management, several articles were also excluded. Studies on politics and media in countries such as Colombia (Murillo, 2003), Zimbabwe (Mhiripiri, 2011), and Brazil (Leal, 2009) were only tangentially pertinent; although they discussed the benefits of radio for discourse formation and social change, they did not provide any insight into the ways in which stations are funded to achieve these objectives. Other studies focusing on the relationship between community radio and mental health (Bonini, 2005; Meadows \& Foxwell, 2011), empowerment and social change (Jallov, 2004; Wagg, 2004), democracy and ethics (Bresnahan, 2007; Gaynor \& O'Brien, 2011; Rennie, Berkeley, \& Murphet, 2010), as well as regulation and policy issues (Coyer, 2006) in countries such as Thailand (Elliott, 2010; Magpanthong \& McDaniel, 2011) also failed to provide information relevant to the financial context of nonprofit radio, despite explaining the benefits of the radio sector itself. For example, Evan Light (2012) provides insight into the regulatory framework for community media in Canada, but only by way of introducing another topic: community radio participation in Québec.

Studies on radio audiences in countries such as Australia (Ewart, 2012) and the United States (Conti, 2011) are not as prevalent in the literature and warrant further study. Cynthia Conti (2011) describes the relationship between low-powered FM non-commercial stations and the local communities they serve. Offering relevant content about the locations they serve, having to find volunteers in those areas, and asking the same people for donations has not resulted in sustained interest of the stations and raises questions related to requirements to finance them. This is the case in many countries, including Canada, where the "grand idea" for nonprofit stations is valued by most, but made to be marginal by forcing au- 


\section{Bonin-Labelle \& Demers (2019)}

diences to sustain stations without first determining if there is an ongoing interest to support them through listenership, financial backing, and volunteerism. The issues described by Conti (2011) need more exploration, as does the use of audience measurement, which, traditionally, has been primarily used by the commercial sector, which can afford the consulting services required to gather this data. Though not directly related to the study at hand, the examination of audience research in the field does reveal some preconceived notions about the sector and how it is meant to sustain itself. In other words, the ideal scenario would include active audiences willing to provide enough ongoing support for stations to justify the funding and even the licences themselves.

The most prevalent form of research on community radio worldwide is done through overviews and case studies. Some of the most recent country-based case studies include Australia (Forde, Meadows, \& Foxwell, 2003; O'Connor, 2012), Bolivia (O'Connor, 2004), Brazil (Torres, 2012), Colombia (Rodríguez \& El Gazi, 2007), India (Sharma, 2011), Ireland (Day, 2009), Nepal (Banjade, 2006), Senegal (Smirès, 2011), Spain (Bergés, 2012; Escudero, 2003), South Africa (Bosch, 2007), Sri Lanka (Seneviratne, 2011), Thailand (Elliott, 2010), the United States (Dunaway, 1998), and Uruguay (Light, 2011). In addition, there are overviews of organizations, such as the World Association of Community Radio Broadcasters, known as AMARC (Diasio, 2010), or specific groups such as Indigenous communities (Alia, 2004). Without going into specific details about each one, it is important to highlight some of their commonalities, differences, and, more importantly, what they say about funding.

Most of these studies outline the development of their country's community radio sector (see, for example, Cammaerts, 2009; Elliott, 2010; Forde, Meadows, \& Foxwell, 2003). In terms of methodology, the majority include case studies of stations within the larger country case study. In Light's (2011) study on community stations in Uruguay, for example, he uses four stations from an initial corpus of twelve to highlight the diversity of radio within the country as a whole. Rosemary Day's (2009) work is another example where an overview of the practices of six stations in Ireland is described to provide examples of the larger context.

Despite using a similar methodology and describing a country's community radio history through a particular lens, these studies all have a different focus. Day (2009) focuses on stations' ability to facilitate participation, whereas Yasmine Smirès (2011) uses the Senegalese example to highlight the space provided to women on the airwaves. And although these cases serve as a testament to the breadth of experiences across nations and to the wonderful accomplishments of the sector, there are some stunning similarities when it comes to funding.

Studies that discuss funding all attest that it is scarce and that stations must resort to all kinds of creative fundraising activities. Tanya Bosch (2007), for example, describes a radio education workshop for children in South Africa funded mostly by donations with other funds generated through productions and space rentals. In describing the situation in Senegal, Smirès (2011) touches on problems, similar to those felt by Canadian stations, where funding is earmarked for programs and projects that are mostly limited in their duration. Senegalese stations are also dependent on advertising and donations to maintain technology, pay electrical costs, and remunerate staff (Smirès, 2011). Technology requires constant financing for stations, and it can be difficult to keep up to date with current trends and even to find funds to improve existing technology infrastructure. Even in Australia, where federal funding is available for community stations, Susan Forde, Michael Meadows and Kerrie Foxwell (2003) describe an unviable situation where stations are perceived as any other business, thereby disregarding the stations' mandate. This is felt in Canada, as well, particularly in the province of Québec, where funding requirements force stations to adopt a particular business model, structure, and even sound that resembles that of commercial stations. Each of these case studies basically recounts a story of radio being "forced to operate in the margins" (Cammaerts, 2009, p. 635). 


\section{Bonin-Labelle \& Demers (2019)}

Despite these various comments about funding or lack thereof, none of the studies consulted provide a sustained discussion on funding or provide empirical evidence gathered for this purpose. The World Association of Community Radio Broadcasters (AMARC) has been a pillar in engaging with community radio worldwide. As Francesco Diasio (2010) and others (Jankowski, 2003, for example) explain, AMARC assists with many policy-related issues, and it forges relationships, networks, as well as communities of knowledge and practice. Although funding is an important issue for most players in the sector, it is not an area that is heavily researched at an international level (with the exception of Coyer, 2011), most likely because of station- and country-specific particularities. However, that is not to say that this is not an issue that could benefit from further exploration. On the contrary, there is not an overview of funding structures from this sector that would serve to bolster a worldwide funding initiative. If anything, these studies demonstrate the precariousness of the sector, along with its high reliance on donations and the volatile nature of sustained funding.

Notwithstanding the breadth of research being conducted, the truth remains that the majority of empirical work aims at "describing and analyzing the organization and operation of stations in different contexts," (Gaynor \& O'Brien, 2011, p. 23). This is something that Niahm Gaynor and Anne O'Brien (2011) maintain has to do with research in this field being mostly in its "first generation" (p. 24). It may also be that the originality of the studies prevents generalization. The lack of theoretical models, as described by Nicholas Jankowski (2003), may be another issue to consider. In Jankowski's article, he contends that research conducted on community media is not sufficient enough to derive any viable theoretical models to guide further empirical investigations.

In Canada, the review of existing literature has provided no indication of any academic research discussing the financial or technological situation of the sector. References are limited to various reports from the federal government (see, for example, Government of Canada, Standing Committee on Canadian Heritage, 2003), the regulator (see, for example, CRTC, 2017b), the provincial government (see, for example, Government of Ontario, 2011), consulting firms (see, for example, Cavanagh, 2009), or other civil society organizations (see, for example, Centime Zeleke, 2004) that often make submissions to the CRTC.

These reports generally offer an illustration of how the sector is doing based on examples or testimony from a variety of sources. The CRTC documents provide an overview of sector revenues and expenses in aggregated form, but no evidence of an in-depth analysis of particular elements is ever mentioned. Most of the reports indicate recommendations for financial improvement, such as providing a more robust policy for community radio (Government of Ontario, 2011), but there is little empirical evidence to support these claims and virtually no evidence of the actual value of the existing financial support, not to mention any formal indication of the scope of technological advancements in the sector.

To be quite frank, when discussing media funding in Canada, the discourse belongs to public radio, in other words, the Canadian Broadcasting Corporation (CBC). Studies about nonprofit radio in Canada are scarce. Most of the information available on the topic is buried in books providing general overviews of Canadian broadcasting (Armstrong, 2016) and it is often mentioned in texts about alternative media (Light, 2012). Tom Evans and Laurence Hauttekeete (2008) echo this sentiment and suggest the lack of studies related to "ownership, structure and market shares of local radio stations" (p. 102) is due to a lack of interest in community radio on behalf of policymakers and researchers. In reality, there has not been a call for discussions related to funding community radio outside the discussions at the CRTC that led to the creation of the Community Radio Fund of Canada. A recent book by Brian Fauteux (2015) called Music in Range does compile some of the scattered information on the sector, including historical information about the creation of community radio, and it also explains the most recent regulatory framework for the sector. Its main focus, however, is on music programming, which leaves many paths to be explored and questions to be answered. Despite some researchers' expectations, Canada does 


\section{Bonin-Labelle \& Demers (2019)}

not have an analogous situation to the United States when it comes to research. The available American corpus is far more robust when it comes to discussing public finances.

More recently, however, nonprofit media discussions have been on the rise, particularly in relation to ongoing issues of media concentration and ownership with regards to democracy and the diversity of voices in the media. This topic is also at the heart of a more recent cluster of publications related to the crisis of journalism (see, for example, Edge, 2014; Gasher, Brin, Crowther, King, Salamon, \& Thibault, 2016; Winceck, 2010) that has resulted in newspaper closures and a wave of employment losses throughout the country. This has been pursued empirically by researchers such as April Lindgren, who has been tracking the loss of local news within a mapping project (Local News Research Project, 2019). Though these initiatives are not directly related to nonprofit media, they have included calls for improved funding of the nonprofit sector as a possible alternative to the current news crisis.

In the book Alternative Media in Canada, David Skinner (2012) suggests that there are three views on the sustainability of alternative media, which are known to be alternatives to mainstream media providers. Nonprofit, community, and campus stations are examples of alternative media in Canada. Skinner (2012) describes sustainability as "having the resources to acquire staff, technologies of production, and avenues of distribution, and to develop audiences" (p. 26). The first is that these media are "underdeveloped and generally doomed to remain marginal in the larger social context" (Skinner, 2012, p. 28). Although many of the studies presented here believe nonprofit radio is underdeveloped, they most likely do not believe that it is wholly relegated to the marginal context in which it sometimes finds itself. The second perspective suggests these media "as ebbing and flowing along with the social and political issues that give them form" (Skinner, 2012, p. 28). This seems to be a more realistic perspective of the media at hand. And, finally, the third perspective suggests the media are developing and their marginal status is an important issue, however, it "takes a more critical view of the larger social field in which these media operate and emphasizes addressing the power relations found there" (Skinner, 2012, p. 30).

However helpful in understanding sustainability perspectives, this is not an empirical study into the nonprofit radio sector and does not seek to find the underlying needs of the stations, which in the community radio sector have very little to do with offering an alternative news source to traditional daily news outlets, due to high production and personnel costs. The majority of stations work with a flow of volunteers. Nonetheless, some community radio stations do manage to offer news, but, generally, it is of another variety. Syndicated current affairs programming, such as the biweekly community radio news magazine Groundwire (see King et al., 2016), is more in line with what the nonprofit sector currently offers and is successful in delivering. Podcasting is also a new venue that is being explored, including by many Indigenous producers and artists (Albinati, Bonin-Labelle, Buddle, Gagnon, King, \& Szwarc, 2019), however, these initiatives are outside the realm of traditional radio.

\section{METHODOLOGY}

This study is part of a larger project that included three phases of data collection. The first phase involved semi-structured recorded interviews with five representatives from select radio station associations in the country. These included the Alliance des radios communautaires du Canada (ARC) in Ottawa (Ontario), Missinipi Broadcasting Corporation in La Ronge (Saskatchewan), the Association des radios communautaires du Nouveau-Brunswick in Moncton (New-Brunswick), the Association des radiodiffuseurs communautaires du Québec (ARCQ) in Montréal (Québec) and the National Campus and Community Radio Association (NCRA) in Ottawa (Ontario). The interviews served as a means to develop relationships for future research partnerships, to confirm the project was consistent with the needs of the sector, and to ensure the best possible participation rate among member stations. The decision to interview people from these groups is consistent with anti-oppressive research that promotes time for relationship building and favours a commitment to creating change 


\section{Bonin-Labelle \& Demers (2019)}

from the research conducted (Potts \& Brown, 2016). This approach is essential to study in this field, given its history and position among sectors, particularly in Canada. These interviews also yielded additional general information about management and financial reporting for their member stations, which serve as a benchmark for the additional data being collected through financial statements (phase 2). Finally, participants in phase two were invited to answer surveys about representation, governance, and technology at a later date (phase 3) to delve deeper into topics mentioned in the semistructured interviews and to prepare for the future dissemination of the research within the communities as part of the principal investigator's commitment to foster change and dialogue within the sector based on the research outcomes.

Phase 2, which is documented in this article, involved contacting 183 stations managers who, to the best of our knowledge, represented the entire population of nonprofit licenced radio stations in Canada at the time of our research, to determine their interest in participating in the study. There may be a discrepancy in relation to the number based on the time the total number was calculated, category definitions used here, and the documents made available by the CRTC at the time of the count. Since, as previously mentioned, the CRTC does not always have an up-to-date tally of its licenced stations, this number represents the total number of stations noted through a detailed analysis of the CRTC website's list of stations, licences, and relevant documentation. Although in the United States, researchers can scan tax return forms, this is not the case in Canada. Very little information on nonprofit media organizations is public. The only financial statements available are those provided to the CRTC. So far, financial information provided to researchers has been in aggregated form through its monitoring reports or in aggregated form through formal requests, but it is never as specific as what stations provide nor is it as detailed as a formal financial report. Some nonprofit organizations, such as Powered by Data or Sector Source, have assisted researchers and government departments to make their data more accessible, but this does not guarantee the data is made available. So far, the only source for CRTC information is what is provided on its website or through its monitoring reports. Consequently, this study relies on the voluntary disclosure of financial statements provided by the radio stations themselves. In total, 62 station managers voluntarily supplied the research team with their consent forms and financial statements for the three years between the beginning of the program in 2012 and 2015. These documents became the main objects of analysis for this phase.

The documents were analyzed thematically based on the categories of regular financial statements and the various fundraising subcategories (for example: bingo, art auction) were coded to better understand the language being used to document finances in the sector.

A database of the data was then created using Microsoft Excel to allow for an overall analysis of the sector. Data was then aggregated for analysis to avoid identifying individual stations as an agreement of anonymity was required. The results relevant to the topic at hand are presented in the next section.

\section{RESULTS}

As can be observed throughout the tables, the sample size is not always consistent. This is because some of the reporting stations were unable to provide their financial statements for every year being studied. Consequently, the average, median, and standard deviation are provided where possible to compare the stations among themselves and a specific station's situation from one reporting year to another. Otherwise, the tables demonstrate the data aggregated by region for all the stations reporting in the sample. To maintain anonymity, the comparative tables detailing the data for stations that have benefited from grants for projects involving technology were aggregated for the country as a whole. Failure to do this would have resulted in the possibility of identifying some stations due to the small number of stations within the sample that have received funding. 


\section{Revenues}

Revenues for the entire sample remain generally stable year over year, with the difference between the averages of $\$ 11,795$ to $\$ 13,217$. The year reporting the best revenues is 2013 with an average of $\$ 252,315$ (see Table 1).

Table 1. Average, median, and standard deviation of revenues and expenses for all nonprofit radio stations benefiting from funding for technology projects

\begin{tabular}{|l|l|l|l|l|l|l|l|l|}
\hline & \multicolumn{2}{|c|}{2012} & \multicolumn{2}{c|}{2013} & \multicolumn{2}{c|}{2014} & \multicolumn{2}{c|}{2015} \\
\hline & Revenues & Expenses & Revenues & Expenses & Revenues & Expenses & Revenues & Expenses \\
\hline Canada & $241,141(41)$ & 232,630 & $252,315(57)$ & 237,298 & $239,098(59)$ & 241,626 & $227,303(31)$ & 220,247 \\
\hline Median & 175,683 & 173,571 & 152,241 & 145,174 & 132,199 & 166,420 & 174,609 & 160,607 \\
\hline $\begin{array}{l}\text { Standard } \\
\text { Deviation }\end{array}$ & $238,478.59$ & $227,164.12$ & $309,620.67$ & $303,577.02$ & $310,083.60$ & $307,305.46$ & $194,221.86$ & $190,372.49$ \\
\hline & & & & & & & & \\
\hline Average & $215,045(14)^{2}$ & 195,930 & $291,897(20)$ & 273,460 & $255,829(22)$ & 276,378 & $207,255(9)$ & 190,296 \\
\hline Median & 206,736 & 173,571 & 185,428 & 177,183 & 151,692 & 175,358 & 202,846 & 183,200 \\
\hline $\begin{array}{l}\text { Standard } \\
\text { Deviation }\end{array}$ & $142,352.62$ & 128,377 & $388,169.02$ & $395,829.38$ & $376,957.60$ & $390,998.80$ & $102,137.84$ & $99,645.29$ \\
\hline
\end{tabular}

Notes: 1) Sample size for every specific year. The sample is built on the total revenues listed in the revenue categories listed in the statements of operations section of the financial statements provided for the study. 2) Sample size for every specific year. The sample is built on both the stations that received funds for technology projects from the Radiometres program and the revenue categories listed in the statements of operations section of the financial statements provided for the study. Every station that received funding during the 2012 to 2015 period is included in the sample in order to analyze the evolution of revenues for the entire period.

The average revenue for the subsample of stations that benefited from the CRFC grants aiding technology projects are more wide-ranging. The difference between averages varies in increments of $\$ 76,852, \$ 36,068$, and $\$ 48,574$. As for the entire sample, the best reporting year is 2013 , where the average lies at $\$ 291,897$ (see Table 1). In both cases, 2015 was the worst reporting year, following a steady decline through 2014. The entire sample reported $\$ 227,303$ for 2015 , while the stations that received funding for technology projects averaged $\$ 207,255$. Although the CRFC does not have a mandate to fund technology, it has, inadvertently, aided in funding these types of initiatives by the types of projects funded. Technology projects, for the purpose of this study, represent any kind of initiative involving technology, from upgrading technology to using technology to modernize a specific task or activity. For example, digitizing a music collection could be a technology project.

\section{Table 2. Breakdown of revenue categories of all participating nonprofit radio stations in Canada}

\begin{tabular}{|l|l|l|l|l|}
\hline & $\mathbf{2 0 1 2}(\mathbf{4 1})^{1}$ & $\mathbf{2 0 1 3}(\mathbf{5 7})$ & $\mathbf{2 0 1 4}(\mathbf{5 9 )}$ & $\mathbf{2 0 1 5}(\mathbf{3 1})$ \\
\hline Student contributions & $1(21.4 \%)$ & $1(22.4 \%)$ & $1(21.3 \%)$ & $1(27 \%)$ \\
\hline Advertising & $2(16.4 \%)$ & $2(20.2 \%)$ & $2(20.4 \%)$ & $4(10.6 \%)$ \\
\hline Donations $^{2}$ & $3(12.4 \%)$ & $5(7 \%)$ & $5(10.3 \%)$ & \\
\hline Miscellaneous/other $^{3}$ & $4(11 \%)$ & $4(9.7 \%)$ & $4(11.7 \%)$ & $5(9.3 \%)$ \\
\hline Grants & $5(10.7 \%)$ & $3(15.6 \%)$ & $3(16.1 \%)$ & $2(14.1 \%)$ \\
\hline Fundraising & & & & $3(13.3 \%)$ \\
\hline
\end{tabular}

Notes: 1) Sample size for every specific year. The sample is built on the revenue categories listed in the statements of operations section of the financial statements provided for the study. 2) The categories mentioned here reflect the uses noted by the stations in their statements of operations. 3) Includes both the amounts indicated under the Miscellaneous category in the statements of operations, as well as the amounts undisclosed by stations that did not break down their revenues in their financial statements. 
However, the CRFC (2019) only allows five percent of a total grant to be spent on technology and does not promote grants for technology funding purposes.

Aside from the CRFC grants, stations have reported financing their operations through a variety of activities. Although the level of diversity was interesting, the top five categories reported for each year always amounted to around 70 percent of total station revenues (see Table 2). The main revenue categories were also relatively stable and included student contributions, advertising, donations, grants, and categories disclosed as "miscellaneous—other." Only in 2015 are the top five categories different, with donations being swapped out for fundraising initiatives. Student contributions and advertising revenues regularly account for more than 20 percent of total revenues for campus stations.

When looking specifically at stations that have received funding for a technology project, the situation is somewhat different, as there are more categories that find their way into the top five (see Table 3). The same six mentioned earlier (student contributions, advertising, donations, miscellaneous/other, grants and fundraising) for the entire sample are still present, but they are joined by the membership and sponsorship categories, although these two only become relevant in 2015. This subsample also displays a greater concentration of the revenues through its top categories. A $70 \%$ revenue concentration of the full sample changes to over 80 percent of the revenue coming from the top categories. Student contributions make up the most important part of these revenues, as they represent

Table 3. Breakdown of top five revenue categories for participating nonprofit radio stations benefiting from funding for technology projects

\begin{tabular}{|l|l|l|l|l|}
\hline & $\mathbf{2 0 1 2}(\mathbf{1 4})^{\mathbf{1}}$ & $\mathbf{2 0 1 3}(\mathbf{2 0})$ & $\mathbf{2 0 1 4}(\mathbf{2 2})$ & $\mathbf{2 0 1 5}(\mathbf{9})$ \\
\hline Miscellaneous $^{2}$ & $1(27.7 \%)$ & $4(10.6 \%)$ & $3(17.5 \%)$ & \\
\hline Student contributions $^{3}$ & $2(26.5 \%)$ & $1(34 \%)$ & $1(29.4 \%)$ & $1(45.8 \%)$ \\
\hline Grants & $3(10.9 \%)$ & $2(17.2 \%)$ & $2(18.5 \%)$ & $2(15.7 \%)$ \\
\hline Donations & $4(10.1 \%)$ & $5(8.1 \%)$ & $5(6.6 \%)$ & \\
\hline Memberships & $5(6.4 \%)$ & & & \\
\hline Advertising & & $3(10.7 \%)$ & $4(14 \%)$ & $4(9.4 \%)$ \\
\hline Fundraising & & & & $3(11.8 \%)$ \\
\hline Sponsorship & & & & $5(4.4 \%)$ \\
\hline
\end{tabular}

Notes: 1) Sample size for every specific year. The sample is built on both the stations that received funds for technology projects from the Radiometres program and the revenue categories listed in the statements of operations section of the financial statements provided for the study. Every station that received funding during the 2012 to 2015 period is included in the sample in order to analyze the evolution of revenues for the entire period. 2) The categories mentioned here reflect the uses noted by the stations in their statements of operations. 3) Includes both the amounts indicated under the Miscellaneous category in the statements of operations, as well as the amounts undisclosed by stations that did not break down their revenues in their financial statements.

\section{Table 4. Average portion of total revenues coming from grants for all participating nonprofit radio stations by region}

\begin{tabular}{|l|c|c|c|c|c|c|c|c|}
\hline & 2012 & Sample $^{1}$ & 2013 & Sample & 2014 & Sample & 2015 & Sample \\
\hline Atlantic $^{2}$ & $7.56 \%$ & 9 & $14.47 \%$ & 12 & $14 \%$ & 12 & $12.94 \%$ & 3 \\
\hline Québec & $31.1 \%$ & 7 & $29.51 \%$ & 7 & $31.4 \%$ & 7 & $30.74 \%$ & 5 \\
\hline Ontario & $2.75 \%$ & 9 & $9.7 \%$ & 16 & $9.89 \%$ & 15 & $13.27 \%$ & 8 \\
\hline West $^{3}$ & $7.88 \%$ & 16 & $16.73 \%$ & 22 & $15.94 \%$ & 25 & $9.28 \%$ & 15 \\
\hline Total & & 41 & & 57 & & 59 & & 31 \\
\hline Average & $10.65 \%$ & & $15.56 \%$ & & $16.4 \%$ & & $14.13 \%$ & \\
\hline Median & $2.14 \%$ & & $6.11 \%$ & & $7.11 \%$ & & $4.68 \%$ & \\
\hline $\begin{array}{l}\text { Standard } \\
\text { deviation }\end{array}$ & 18.61 & & 22.73 & & 20.72 & & 20.5 & \\
\hline
\end{tabular}

Notes: 1) Sample size for every specific year. The sample is built on the grants category (also named bursaries in some instances) included in the statements of operations section in the financial statements provided by the participating stations for the study. 2) The Atlantic region includes the provinces of Newfoundland and Labrador, Nova Scotia, New Brunswick, and Prince Edward Island. 3) The West region includes the provinces of Manitoba, Saskatchewan, Alberta, and British Columbia, as well as the territories of Yukon, Nunavut, and the Northwest Territories. 


\section{Bonin-Labelle \& Demers (2019)}

between 26.5 percent and 45.8 percent of the total, while the other categories mostly remain stable before declining or leaving the top five in 2014 and 2015.

Grants, the majority of which are restricted to particular programs, are one of the main sources of revenue for nonprofit stations. However, they are unequally distributed across Canada (see Table 4). Grants consistently account for the largest portion of revenues for stations from the province of Québec. They receive around 30 percent of their revenues from grants as opposed to a modest 10 percent for the rest of Canada. As previously mentioned, these stations receive an operating grant from the government of Québec (Culture et Communication Québec, 2016; Lévesque, 2018). The years 2013 and 2014 represent the most significant grant revenues in this region, about 16 percent of the total, which is up five percent from 2012. Of importance is the standard deviation, which remains around 20 for the entire period studied. This widely separates the most and least favoured stations.

In the case of stations having received money for technology projects, the most important years are also 2013 and 2014 (see Table 5). Compared to the entire sample, these stations did slightly better with their total grant revenues hovering around 18 percent, while 2012 and 2015 happened to be similar to the entire sample situation at around 11 percent and 14 percent, respectively. The subsample increased by seven percent in grants from 2012 to 2013. Nonetheless, similar to the entire sample, the standard deviation, except for 2012, is still 20.

\section{Expenses}

Expenses present more significant variations. From 2012 to 2014, the average expenses for the entire sample increased from one year to the next, but between 2014 and 2015, the average expenses dropped by $\$ 21,379$ (see Table 1). This reality was more prominent for the subsample of stations receiving funding for technological projects, as the variation of the average total expenses mirrored that of the total rev-

\section{Table 5. Average portion of revenues for stations with technological improvements subsidized by the CRFC through the Radiometers grants compared to the entire sample of stations}

\begin{tabular}{|l|l|l|l|l|}
\hline & \multicolumn{1}{|c|}{$\mathbf{2 0 1 2}$} & \multicolumn{1}{|c|}{$\mathbf{2 0 1 3}$} & \multicolumn{1}{|c|}{$\mathbf{2 0 1 4}$} & \multicolumn{1}{c|}{$\mathbf{2 0 1 5}$} \\
\hline Canada & $10.65 \%(41)^{1}$ & $15.56 \%(57)$ & $16.4 \%(59)$ & $14.13 \%(31)$ \\
\hline Average & $10.87 \%(14)^{2}$ & $17.17 \%(20)$ & $18.54 \%(22)$ & $13.68 \%(9)$ \\
\hline Median & $3.34 \%$ & $10.33 \%$ & $14.06 \%$ & $0.58 \%$ \\
\hline $\begin{array}{l}\text { Standard } \\
\text { deviation }\end{array}$ & 15.99 & 23.01 & 22.69 & 20.86 \\
\hline
\end{tabular}

Notes: 1) Sample size for every specific year. The sample is built on the grants category (also named bursaries in some instances) included in the statement of operations section in the financial statements provided by the participating stations for the study. 2) Sample size for every specific year. The sample is built on both the stations that received funds for technology projects from the Radiometres program and the revenue categories listed in the statements of operations section of the financial statements provided for the study. Every station that received funding during the 2012 to 2015 period is included in the sample in order to analyze the evolution of revenues for the entire period.

\section{Table 6. Breakdown of the top five expense categories for participating nonprofit radio stations}

\begin{tabular}{|l|l|l|l|l|}
\hline & $\mathbf{2 0 1 2 ( 4 1 )}$ & $\mathbf{2 0 1 3}(\mathbf{5 7})$ & $\mathbf{2 0 1 4}(59)$ & $\mathbf{2 0 1 5}(31)$ \\
\hline Salaries $^{2}$ & $1(46.3 \%)$ & $1(43.9 \%)$ & $1(43.1 \%)$ & $1(40.8 \%)$ \\
\hline Miscellaneous $^{3}$ & $2(31.8 \%)$ & $2(34.2 \%)$ & $2(35.5 \%)$ & $2(38.2 \%)$ \\
\hline Utilities $^{4}$ & $3(11.1 \%)$ & $3(10 \%)$ & $3(7.8 \%)$ & $3(10.8 \%)$ \\
\hline Amortization & $4(3.7 \%)$ & $5(3.3 \%)$ & $4(5 \%)$ & $4(4.5 \%)$ \\
\hline Telecommunications & $5(3.2 \%)$ & $4(3 \%)$ & $5(3.8 \%)$ & $5(2.2 \%)$ \\
\hline
\end{tabular}

Notes: 1) Sample size for every specific year. The sample is built on the revenue categories listed in the statements of operations section of the financial statements provided for the study. 2) The categories mentioned here reflect the uses noted by the stations in their statement of operations. 3) Includes both the amounts indicated under the Miscellaneous category in the statement of operations, as well as a number of categories for which values were too small to be rounded up to a significant decimal and expense amounts undisclosed by stations. 4) The Utilities category was aggregated from the data listed under the "electricity," "postage," office supplies," heating," and "furniture" categories listed in the statements of operations. 
enues discussed earlier. Expenses dramatically increased by $\$ 77,530$ for these stations from 2012 to 2013, before dropping $\$ 86,082$ from 2014 to 2015 . Such variations were not found in the compilation of the top five categories of expenses reported by these participating stations. Similar to the total revenues, the top five expense categories remain quite static for the entire period studied. Salaries, miscellaneous, utilities, amortization, and telecommunications make up the list, with salaries never letting go of the top spot or dropping below the 40 percent mark (see Table 6). These expense categories also end up totalling over 90 percent of the expenses reported by the participating stations.

The situation is somewhat similar when analyzing the top five expense categories of the stations making up the subsample (see Table 7). The categories remain the same except for the complete disappearance of the telecommunications category, which is replaced by insurance in 2012 , 2013, and 2015, and by professional expenses in 2014. These main expense categories make up the bulk of the total expenses of the stations; they add up to around 90 percent for the entire period studied. Of those categories, salaries have the biggest impact, making up as much as 50 percent of total expenses in 2012 and 2013 before declining slightly to 42 percent in 2015.

\section{Surplus and deficit}

The financial landscape would not be complete without a picture of the debt carried by nonprofit radio stations. Concerning the main sample, the situation remains stable from 2012 to 2015. Deferred revenues and accounts payable remain the two main categories in this regard, adding up to anywhere between 47 percent and 66 percent
Table 7. Breakdown of the top five expense categories for participating nonprofit radio stations benefiting from funding for technology projects

\begin{tabular}{|l|l|l|l|l|}
\hline & $\mathbf{2 0 1 2}(\mathbf{1 4})^{1}$ & $\mathbf{2 0 1 3}(\mathbf{2 0})$ & $\mathbf{2 0 1 4}(\mathbf{2 2 )}$ & $\mathbf{2 0 1 5}(\mathbf{9})$ \\
\hline Salaries $^{2}$ & $1(52 \%)$ & $1(51.1 \%)$ & $1(46.1 \%)$ & $1(41.9 \%)$ \\
\hline Miscellaneous $^{3}$ & $2(26.6 \%)$ & $2(32.5 \%)$ & $2(36.8 \%)$ & $2(39.3 \%)$ \\
\hline Utilities $^{4}$ & $3(10.8 \%)$ & $3(5.9 \%)$ & $3(7.3 \%)$ & $3(10.2 \%)$ \\
\hline Amortization & $4(4.3 \%)$ & $4(3.5 \%)$ & $4(4.6 \%)$ & $4(4 \%)$ \\
\hline Insurances & $5(2 \%)$ & $5(1.8 \%)$ & & $5(1.7 \%)$ \\
\hline Professional expenses & & & $5(1.8 \%)$ & \\
\hline
\end{tabular}

Notes: 1) Sample size for every specific year. The sample is built on both the stations that received funds for technology projects from the Radiometres program and the revenue categories listed in the statements of operations of the financial statements provided for the study. Every station that received funding during the 2012 to 2015 period is included in the sample in order to analyze the evolution of expenses for the entire period. 2) The categories mentioned here reflect the uses noted by the stations in their statement of operations. 3) Includes both the amounts indicated under the Miscellaneous category in the statements of operations, as well as a number of categories for which values were too small to be rounded up to a significant decimal and expense amounts undisclosed by stations. 4) The Utilities category was aggregated from the data listed under the "electricity," "postage," office supplies," heating," and "furniture" categories listed in the statements of operations.

\section{Table 8. Breakdown of the debt situation of all participating nonprofit radio stations}

\begin{tabular}{|l|l|l|l|l|}
\hline & $2012(41)^{1}$ & $\mathbf{2 0 1 3}(\mathbf{5 7})$ & $\mathbf{2 0 1 4}(\mathbf{5 9 )}$ & $\mathbf{2 0 1 5}(\mathbf{3 1})$ \\
\hline Deferred revenue & \\
\hline Accounts payable & $1(33 \%)$ & $2(24 \%)$ & $1(25 \%)$ & $1(41 \%)$ \\
\hline Long-term debt & $2(30 \%)$ & $1(31 \%)$ & $2(22 \%)$ & $2(25 \%)$ \\
\hline Bank loan & $3(14 \%)$ & $3(13 \%)$ & $3(19 \%)$ & $3(11 \%)$ \\
\hline $\begin{array}{l}\text { Loan without interest } \\
\text { payable upon demand }\end{array}$ & $4(7 \%)$ & $5(5 \%)$ & & $5(4 \%)$ \\
\hline $\begin{array}{l}\text { Portion of long-term debt } \\
\text { renewable within one year }\end{array}$ & $5(3 \%)$ & & $5(8 \%)$ & \\
\hline $\begin{array}{l}\text { Portion of long-term debt } \\
\text { reimbursable within one year }\end{array}$ & & $4(11 \%)$ & $4(10 \%)$ & \\
\hline
\end{tabular}

Notes: 1) Sample size for every specific year. The sample is built on categories included in the statements of financial position listed in the financial statements provided by the participating stations for the study. 2) Deferred revenues are coming from different sources that include: student fees that are earned but have not been paid because of the way fiscal years are set, advertising revenue that was not yet paid once the fiscal year ended, and grant funding, depending on how the grant is to be paid (e.g., a portion given at the start of a project and the rest upon completion). 
of the debt load per year (see Table 8). In addition to these two short-term categories, there is the long-term debt in third place, which experienced an eight percent variation throughout the study period. The categories taking up fourth and fifth places vary between bank loans, loans without interest payable upon demand, long-term debt renewable within the year, and a portion of long-term debt reimbursable within one year.

The subsample presents more significant variations from year to year. From 2012 to 2015, there are 11 different debt categories reported, with accounts payable and deferred revenue being the only categories present in every instance (see Table 9). These two categories make up most of the debt; they account for 40 percent to 61 percent of the total debt during the study period. The only exceptions are in 2013 and 2014, where the "portion of long-term debt renewable within one year" takes the top position, with 38 percent and 33 percent, respectively. This mirrors the appearance of the long-term debt category in fourth place. Both do not appear in 2012 and 2015.
Table 9. Breakdown of the debt situation of all participating nonprofit radio stations benefiting from funding for technology projects

\begin{tabular}{|l|l|l|l|l|}
\hline & $2012(14)^{1}$ & $2013(20)$ & $2014(22)$ & $2015(9)$ \\
\hline Account payables & $1(37 \%)$ & $2(33 \%)$ & $2(24 \%)$ & $1(37 \%)$ \\
\hline Deferred grants & $2(12 \%)$ & & & \\
\hline Deferred revenue & $3(12 \%)$ & $3(7 \%)$ & $3(19 \%)$ & $2(24 \%)$ \\
\hline Current portion of bank loans & $4(5 \%)$ & & & \\
\hline $\begin{array}{l}\text { Loan without interest payable } \\
\text { upon demand }\end{array}$ & & $5(4 \%)$ & $5(5 \%)$ & \\
\hline $\begin{array}{l}\text { Portion of long-term debt } \\
\text { renewable within one year }\end{array}$ & & $1(38 \%)$ & $1(33 \%)$ & \\
\hline $\begin{array}{l}\text { Deferred revenue from real } \\
\text { estate }\end{array}$ & & & & $3(7 \%)$ \\
\hline $\begin{array}{l}\text { Long-term debt due to related } \\
\text { parties }\end{array}$ & $(10 \%)$ & $(6 \%)$ & & $(15 \%)$ \\
\hline Bank loan & & & & $4(8 \%)$ \\
\hline Current portion of bank loans & & & & \\
\hline
\end{tabular}

Notes: 1) Sample size for every specific year. The sample is built on both the stations that received funds for technology projects from the Radiometres program and the revenue categories listed in the statements of operations section of the financial statements provided for the study. Every station that received funding during the 2012 to 2015 period is included in the sample in order to analyze the evolution of revenues for the entire period. 2) Deferred revenues are coming from different sources that include: student fees that are earned but have not been paid because of the way fiscal years are set, advertising revenues that were not yet paid once the fiscal year ended, and grant funding, depending on how the grant is to be paid (e.g., a portion given at the start of a project and the rest upon completion).

Table 10. Surplus and deficit of all participating nonprofit radio stations by region

\begin{tabular}{|l|c|c|c|c|c|c|c|c|}
\hline & \multicolumn{2}{|c|}{2012} & \multicolumn{2}{c|}{2013} & \multicolumn{2}{c|}{2014} & \multicolumn{2}{c|}{2015} \\
\hline & Surplus & Deficit & Surplus & Deficit & Surplus & Deficit & Surplus & Deficit \\
\hline Atlantic $^{2}$ & 3 & 6 & 5 & 7 & 6 & 6 & 2 & 1 \\
\hline Québec & 2 & 5 & 3 & 4 & 4 & 3 & 3 & 2 \\
\hline Ontario & 5 & 4 & 11 & 5 & 13 & 2 & 8 & 0 \\
\hline West $^{3}$ & 14 & 2 & 19 & 3 & 19 & 6 & 13 & 2 \\
\hline Total & $\mathbf{2 4}$ & 17 & $\mathbf{3 8}$ & $\mathbf{1 9}$ & $\mathbf{4 2}$ & 17 & $\mathbf{2 6}$ & $\mathbf{5}$ \\
\hline
\end{tabular}

Notes: 1) Surpluses and deficits were calculated based on the difference between total revenues and total expenses declared in the statements of operations section of the financial statements. 2) The Atlantic region includes the provinces of Newfoundland and Labrador, Nova Scotia, New Brunswick, and Prince Edward Island. 3) The West region includes the provinces of Manitoba, Saskatchewan, Alberta, and British Columbia, as well as the territories of Yukon, Nunavut, and the Northwest Territories. 


\section{Bonin-Labelle \& Demers (2019)}

Aside from the debt situation, there is the question of year-to-year operations. When analyzing Table 10, it is possible to observe that the ratio between all stations experiencing a surplus and those dealing with a deficit (all stations combined) declines progressively from close to one-to-one all the way to five-to-one, leaning in favour of the surplus. The western region stands out the most because, except for 2014, there are never more than two stations in deficit. This is not the case in Eastern Canada, where the Atlantic Provinces and Québec only get back to a positive ratio from 2014 onward. Of note is the 2015 situation for Ontario, when none of the eight participating stations are in a deficit.

Finally, the surplus and deficit landscape for the subsample shows a positive situation. There are almost twice as many stations experiencing a surplus than a deficit (see Table 11). The year 2013 was the worst in the sample. Indeed, the situation improves through 2014 and 2015. Concerning the latter year, only one station of the subsample is in deficit.

Table 11. Surplus and deficit of all participating nonprofit radio stations benefiting from funding for technology projects

\begin{tabular}{|l|c|c|c|c|c|c|c|c|}
\hline & \multicolumn{2}{|c|}{2012} & \multicolumn{2}{c|}{2013} & \multicolumn{2}{c|}{2014} & \multicolumn{2}{c|}{2015} \\
\hline & Surplus $^{1}$ & Deficit & Surplus & Deficit & Surplus & Deficit & Surplus & Deficit \\
\hline Total & 11 & 3 & 12 & 8 & 15 & 7 & 8 & 1 \\
\hline
\end{tabular}

Note: 1) Sample size for every specific year. The sample is built on both the stations that received funds for technology projects from the Radiometres program and the revenue categories listed in the statements of operations section of the financial statements provided for the study. Every station that received funding during the 2012 to 2015 period is included in the sample in order to analyze the evolution of revenue for the entire period.

\section{DISCUSSION}

Nonprofit radio is one of the most important sectors in radio as it "gives voice to the voiceless, ... serves as the mouthpiece of the marginalized and is at the heart of communication and democratic processes within societies" (Fraser \& Restrepo Estrada, 2001, p. iii). However, it is surprising how little attention the sector has been given in academic research. And, as was stated in a UNESCO (Scarone Azzi \& Sánchez, 2003) report on community radio broadcasting legislation, since Canada's community stations are a recognized part of the broadcasting system, any new regulatory developments should take into account the challenges the sector faces, including new technologies and "if they are to really meet the needs of the sector [these], must be adapted to technical, cultural and political changes" (p. 106). This study sought to do just that in determining how the current provisions for technological financial support through the CRFC grants have fared. In so doing, it was possible to compare the value of this funding for long-term sustainable technological plans among stations that received funding as opposed to those that did not.

This study demonstrates that there was no significant impact on revenues due to the funding stations received through the CRFC. However, the grants received did have an impact on expenditures. Stations that received a grant were more likely to invest in long-term projects that cost much more than what was covered by the grants obtained. They were also much more likely to finance themselves through long-term loans they could renew within a year. This gave them the opportunity to wait for their funding or attempt to find other revenues. Consequently, this demonstrates that the expenses would have been incurred whether the grant money was received or not and that the technological projects were required, this despite the fact that the CRFC only accounts for five percent of a station's budget toward new technology. That said, stations would have had to find money for the technological projects whether or not they were successful with their grant applications. This situation seems to be related to the income effect. When a person's income increases, so does their discretionary income. With this discretionary money, the person is able to choose to buy more of the same goods, more expensive goods, or something else (known as the Slutsky substitution effect (Income Effect, 2011). When this income 


\section{Bonin-Labelle \& Demers (2019)}

decreases, the person can choose to buy cheaper goods or less goods (Income Effect, 2011). Following this logic, it is presumable that stations that did not obtain the grant would probably have gone through with their projects, but possibly on a smaller scale or using cheaper technological options, as they must keep up with technological demands. To be sure, however, further interviews with participating stations would be required. Those that obtained the grant were most likely able to pursue projects with better materials and on a larger scale, based on the evidence provided in the financial statements.

In terms of expenses, it was also noted that as stations started to become emboldened in their spending, they tended to have more expenses related to professional fees. In 2013, the Canadian Not-for-profit Corporations Act (Canadian Ministry of Justice, 2009) was modified. An organization that receives income of more than $\$ 10,000$ from public sources is considered to be soliciting. Depending on its revenues, this organization may have to maintain audited financial statements or even retain professional accounting services (Hennessy, 2013; Welch LLP, 2017). This could be one of the reasons why some stations began spending on professional services. However, it could also be because they had requirements from their bank in order to receive a loan or simply because the sector as a whole is moving toward a more professional model. This model increasingly needs professionals, such as accountants, and audited statements in order to access money from investors, or even to solicit donations from everyday citizens who are now better informed about organizations because of the internet.

In terms of sustainability, this study has demonstrated that most stations continue to rely on grant money rather than finding ways of becoming sustainable. Grants in this study seem to have a disincentive effect. In receiving grants, stations with stable revenues did not seek out additional money. Out of the 108 stations that received funding through the Radiometers grant competition, only 28 had applied for funding once during the 2012-2015 period. All other stations have applied at least twice, which suggests that the current system is not allowing for stations to become sustainable.

Matching funds could assist in this problem, however, the sector would need to be cautious about where the initial money is obtained. As a study by Brooks (2000) demonstrates, there is a strong relationship between how much people are willing to give based on the sector and the type of subsidy involved. In this case, it would be difficult to determine the exact effects because the CRFC is technically not made up of "real" public money but rather money from the commercial sector and well-to-do stations that is funnelled to the nonprofit sector by means of the regulations of a public agency (the CRTC). It is difficult to tell how this complicated arrangement could be made clear to the average person or organization for marketing purposes.

In trying to explain why some stations were more successful than others in securing funds, it was revealed that nine out of the 22 stations in the sample that received funds from the Radiometers competition for projects with technological components were student stations. Overall, 22 student stations participated in the study. Therefore, 41 percent of these stations ( 9 out of 22) have received funding in comparison to 32.5 percent (13 out of 40 ) of regular community radio stations. One would need to analyze the actual applications for funding to determine what factors could explain the advantage of campus stations. It would also be beneficial to document arguments used to attribute the funds during the closed-door meetings of grant adjudicators.

\section{LIMITATIONS AND FURTHER RESEARCH}

It would have been helpful to have financial statements for all years being reported for the sample population or even better for the entire population. However, since the CRTC does not make financial statements public, even though all stations must provide them, and since nonprofit stations are generally run by volunteers, the research team was forced to work with what it had. It took more than a year to obtain the financial statements alone. Having all the statements 


\section{Bonin-Labelle \& Demers (2019)}

would have provided a more accurate illustration of the financial situation of stations benefiting from grants for technological projects. Further research involving a longitudinal study would be interesting to determine, for example, how many times a station applies for grant money over a ten-year period, what it does with this money, and how this impacts its financial health over time. It would also give the CRFC a better indication of the value and uses of its competitions.

It would also be relevant to compare the disincentive effects of the grants with other types of grants by adding a matching funds option, to closely monitor the relationship between loans and grants to find the best situation, and to examine how the nonprofit radio industry fares in comparison to other cultural industries or another sector of nonprofit organizations to improve related policies. Such studies are already being considered in other areas, such as foreign aid to reduce poverty (Inge \& Conceiçāo, 2011).

\section{CONCLUSION}

Conducting this study allowed the creation of an overview of funding through the lens of community media, which provided a means to observe several financial behaviours that can serve as best practices for other nonprofit stations from Canada and abroad. First, although grant money does give stations a boost in the short-term, station managers should think about how this money could be used to benefit stations in the long-term. They should ask themselves if the projects are sustainable on a long-term basis or if short-term investments will provide long-term benefits for the station. By seeing how the grant money can be used to foster long-term objectives, stations should better manage this money and make better decisions when applying for funds.

Second, although the CRFC currently does not require stations to obtain matching funds to receive a grant, stations would benefit from this exercise every time they apply for money. Although the risks for using matching funds have been noted, there are three ways they could provide an incentive for the stations. First, it would allow them to engage in more substantial projects than those possible using only grant money. Second, it would force organizations to obtain feedback about projects in which they are trying to invest. If potential investors are not enthralled by the ideas put forth, it might be that the project is not that exciting or useful. These investors might also provide other ideas that could be of better value to the stations. Finally, matching funds may allow for greater accountability because there are other partners invested in the projects.

All in all, this study shows that nonprofit stations manage to invest in technological projects with or without grants. Since it is not clear what the technological future holds, however, it is difficult to determine if these investments are substantial enough to ensure stations keep up with technology. Long-term financial planning needs to be at the forefront of station management and only further studies would reveal if current governance structures support this type of planning.

\section{NOTES}

1. The CRTC is the Canadian regulatory body for broadcasting and telecommunications. It is an agency at arm's length from the government.

2. The National Campus and Community Radio Association (NCRA), the Alliance des radios communautaires du Canada (ARC du Canada), and the Association des radiodiffuseurs communautaires du Québec (ARCQ).

3. Canadian content development comprises contributions from the commercial and ethnic radio broadcasters earning more than $\$ 1.5$ million in annual revenues to "initiatives that aid in the development and promotion of Canadian musical and spoken word content for broadcast" (CRTC, 2014).

4. These reports are produced annually. They include aggregated financial information about each media sector and provide an overview of the health of the broadcasting and telecommunication industries. They do not include detailed methodology about how numbers are calculated nor are they necessarily produced the same way each year. In other words, it is very difficult to compare them from one year to the next as the information provided varies widely. 


\section{Bonin-Labelle \& Demers (2019)}

5. Although one might expect several government sources to be available to describe the broadcasting sector in Canada, the reality is quite the opposite, especially for the nonprofit sector. A few associations represent member stations, but they only have information on their members and generally only publicly share it with them. The CRTC produces the annual monitoring report, but it does not conform to the same format every year nor does it always contain the same information. Therefore, it is difficult to have a perfect picture of the industry. Also, data on the commission's website is not always up-to-date given its small number of personnel. Statistics Canada also stopped generating data on radio for more than a decade.

6. It would have been ideal to provide geographical information on these stations, but the only resource available is a list generated on the CRTC's website. At writing time, however, it had not been updated since February 2017.

7. In Canada, a college refers to an institution where students receive vocational or technical education for professions such as chef, police officer, hair stylist, or veterinary technician.

8. We have not opted for the "non-commercial radio" designation now used by the CRTC in its last monitoring report as religious stations are not included in this dataset.

9. The Hamelin Line (or the 55th parallel) is a geographic line that is used by the Canadian government to differentiate between Indigenous communities in the north and those in the south. Stations in the north are eligible for funding, whereas those in the South are not. Bruce Girard's (1992) book provides another example of a collection of overviews and case studies from a variety of countries.

\section{REFERENCES}

Albinati, C., Bonin-Labelle, G., Buddle, K., Gagnon, J., King, G., \& Szwarc, J. (2019). Recommendations for a new consultation process and policy for First Nations, Inuit and Métis broadcasting - final report. Ottawa, ON: University of Ottawa. URL: http://hdl.handle.net/10393/39010 [April 29, 2019].

Alia, V. (2004). Indigenous radio in Canada. In A. Crissell (Ed), More than a music box: Radio cultures and communities in a multi-media world (pp. 77-94). New York, NY: Berghahn Books.

Armstrong, R. (2016). Broadcasting policy in Canada. Toronto, ON: University of Toronto Press.

Banjade, A. (2006). Voice to the voiceless in western Nepal: An audience survey of community radio Mandanpokrara. Journal of Development Communication, 17(1), 72-91.

Bergés, S.L. (2012). Spain: An information society without traditional offline community media? Journal of Radio and Audio Media, 19(2), 134-151.

Bonin, G.A. (2010). Accountability and the CRTC: An evaluation of the Canadian commercial radio licence renewal process (1997-2007) [Unpublished doctoral dissertation]. Montréal, QC: McGill University.

Bonin, G.A. (2012). Accountability in the commercial radio sector: Lessons from Canada. Observatorio (OBS*) Journal, $6(2), 1-26$.

Bonini, T. (2005). Crazy radio: The domestication of mental illness over the airwaves. Radio Journal: International Studies in Broadcast \& Audio Media, 3(3), 145-153.

Bosch, T. (2007). Children, culture and identity on South African community radio. Journal of Children and Media, 1(3), 277-288.

Bresnahan, R. (2007). Community radio and social activism in Chile 1990-2007: Challenges for grass roots voices during the transition to democracy. Journal of Radio Studies, 14(2), 212-233.

Brooks, A.C. (2000). Is there a dark side to government support for nonprofits? Public Administration Review, 60(3), 211-218.

Cammaerts, B. (2009). Community radio in the West: A legacy of struggle for survival in a State and capitalist controlled media environment. The International Communication Gazette, 71(8), 635-654.

Canadian Broadcasting Corporation. (2007). Astral Media to buy Standard Radio for \$1.08B. URL: http://www.cbc.ca Inews/business/astral-media-to-buy-standard-radio-for-1-08b-1.646606 [September 2, 2016].

Canadian Ministry of Justice. (2009). Not-for-profit Corporations Act (S.C. 2009, c. 23). URL: http://laws.justice.gc.ca leng/acts/c-7.75/page-1.html\#h-1 [February 23, 2017]. 


\section{Bonin-Labelle \& Demers (2019)}

Canadian Radio-television and Telecommunications Commission. (1990). Public notice 1990- 89. URL: https://crtc.gc .ca/eng/archive/1990/pb90-89.htm [September 27, 2019].

Canadian Radio-television and Telecommunications Commission. (1998). Public notice 1998-62. URL: http://www.crtc .gc.ca/eng/archive/1998/pb98-62.htm [September 6, 2016].

Canadian Radio-television and Telecommunications Commission. (2007). Broadcasting decision CRTC 2007-359. URL: http://www.crtc.gc.ca/eng/archive/2007/db2007-359.htm [September 2, 2016].

Canadian Radio-television and Telecommunications Commission. (2010). Broadcasting regulatory policy CRTC 2010499. URL: http://www.crtc.gc.ca/eng/archive/2010/2010-499.HTM [September 2, 2016].

Canadian Radio-television and Telecommunications Commission. (2013). Broadcasting regulatory policy CRTC 2013-476. URL: http://www.crtc.gc.ca/eng/archive/2013/2013-476.htm [September 2, 2016].

Canadian Radio-television and Telecommunications Commission. (2014). Canadian content development contributions and eligible initiatives. URL: http://www.crtc.gc.ca/eng/general/ccdparties.htm [September 2, 2016].

Canadian Radio-television and Telecommunications Commission. (2017a). Communications monitoring report 2017: Broadcasting sector overview. URL: https://crtc.gc.ca/eng/publications/reports/PolicyMonitoring/2017/cmr2017.pdf [July 18, 2018].

Canadian Radio-television and Telecommunications Commission. (2017b). General plans and reports. URL: http:/l www.crtc.gc.ca/eng/publications1.htm [March 10, 2017].

Canadian Radio-television and Telecommunications Commission. (2018). Communications monitoring report 2018. URL: https://crtc.gc.ca/eng/publications/reports/policymonitoring/2018/index.htm [March 5, 2019].

Cavanagh, R. (2009). International approaches to funding community \& campus radio. URL: http://www.crtc.gc.ca leng/publications/reports/radio/connectus0903.htm [September 9, 2016].

Centime Zeleke, Elleni. (2004). The status of women in community-based radio in Canada. URL: http://ncra.ca/whv Incra-report-women-in-community-radio.pdf [September 9, 2016].

Community Radio Fund of Canada (2019). Radiometers: Guidelines. URL: http://crfc-fcrc.ca/wp-content/uploads /2019/01/RM-1920-01_Guidelines.pdf [September 27, 2019].

Community Radio Fund of Canada. (2018). Funding is offered to support radio production, volunteer training and community participation. URL: http://www.crfc-fcrc.ca/en/home/item/303-funding-is-offered-to-support-radio -production-volunteer-training-and-community-participation [July 18, 2018].

Community Radio Fund of Canada. (2018a). Outcome-based approach. URL: https://crfc-fcrc.ca/en/programs loutcome-based-approach/ [March 7, 2019].

Community Radio Fund of Canada. (n.d.). Program priorities. URL: http://www.crfc-fcrc.ca/en/our-programs/program -priorities [July 18, 2018].

Community Radio Fund of Canada. (n.d.-a). Mandate. URL: http://www.crfc-fcrc.ca/en/about-the-fund/mandate [September 8, 2016].

Community Radio Fund of Canada. (n.d.-b). Radio talent development program. URL: http://www.crfc-fcrc.ca/en/our -recipients/radio-talent-development-program [October 11, 2016].

Community Radio Fund of Canada. (n.d.-c). Youth internship program. URL: http://www.crfc-fcrc.ca/en/our-recipients /youth-internship-program [October 11, 2016].

Community Radio Fund of Canada. (n.d.-d). Youth on air! URL: http://www.crfc-fcrc.ca/en/our-recipients/youth-on-air [October 11, 2016].

Conti, C. (2011). Is anybody listening? Questioning the local bond between LPFM programmers and their audience. Journal of Communication Inquiry, 35(1), 20-36.

Coyer, K. (2006). Community radio licencing \& policy. Global Media and Communication, 2(1), 129-134.

Coyer, K. (2011). Community media in a globalized world: The relevance and resilience of local radio. In M. Raboy \& R. Mansell (Eds), The Handbook of global media and communication policy (pp. 166-179). Hoboken, NJ: Wiley-Blackwell. 


\section{Bonin-Labelle \& Demers (2019)}

Culture et communication Québec. (2016). Aide au fonctionnement pour les médias communautaires. URL:

https://www.mcc.gouv.qc.ca/index.php?id=1997 [September 6, 2016].

Day, R. (2009). Community radio in Ireland: Participation and multiflows of communication. Cresskill, NJ: Hampton Press.

Diasio, F. (2009). AMARC and more than 25 years of community media activism. Telematics \& Informatics, 27(2), $193-195$.

Dunaway, D. (1998). Community radio at the beginning of the 21 st century: Commercialism vs. community power. Javnost-The Public, 5(2), 87-103.

Edge, M. (2014). Greatly exaggerated: The myth of the death of newspapers. Vancouver, BC: New Star Books.

Elliott, P.W. (2010). Another radio is possible: Thai community radio from the grass roots to the global. Radio Journal: International Studies in Broadcast \& Audio Media, 8(1), 7-22.

Escudero, M. (2003). Third sector radio in Spain. Radio Journal: International Studies in Broadcast \& Audio Media, 1(3), 177-192.

Evans, T., \& Hauttekeete, L. (2008). From hero to zero: How commercialism ruined community radio in Flanders. The Radio Journal, 6(2\&3), 95-112.

Ewart, Jacqui. (2012). Exploring the unity in Australian community radio. Media International - Australia, 142, $123-134$.

Fauteux, B. (2015). Music in range. Waterloo, ON: Wilfrid Laurier University Press.

Forde, S., Meadows, M., \& Foxwell, K. (2003). Community radio \& local culture: An Australian case study. Communications, The European Journal of Communication Research, 28(3), 231-252.

Fraser, C., \& Restrepo Estrada, S. (2001). Community radio handbook. Bangkok Office and Regional Bureau for Education in Asia and the Pacific: UNESCO.

Gasher, M., Brin, C., Crowther, C., King, G., Salamon, E., \& Thibault, S. (2016). Journalism in crisis: Bridging theory and practice for democratic media strategies in Canada. Toronto, ON: University of Toronto Press.

Gaynor, N., \& O'Brien, A. (2011). Community radio in Ireland. Javnost-The Public, 18(3), 23-27.

Girard, B. (1992). A passion for radio: Radio waves and community. Montréal, QC: Black Rose Books.

Government of Canada. Standing Committee on Canadian Heritage. (2003). Our cultural sovereignty: The second century of Canadian broadcasting. URL: http://www.parl.gc.ca/content/hoc/Committee/372/HERI/Reports /RP1032284/herirp02/herirp02-e.pdf [September 9, 2016].

Government of Ontario. Commissariat aux services en français. (2011). Étude sur les radios communautaires francophones de l'Ontario : Éléments clés de la vitalité des communautés. URL: http://csfontario.ca/wp-content /uploads/2011/04/Etude-radios-communautaires.pdf [September 9, 2016].

Hennessy, M. (2013). Changes to the nonprofit legislation: The Canada Not-for-profit Corporations Act. URL: https:// www.spcottawa.on.ca/sites/all/files/Changes\%20in\%20NFP\%20Legislation\%20-FINAL-\%20Dec\%202013.pdf [February 23, 2017].

Income Effect. (2011). Business dictionary. URL: http://www.businessdictionary.com/definition/income-effect.html Inge, K., \& Conceiçāo, P. (2011). Using aid instruments more coherently: Grants and loans. In P. Conceiçāo \& K. Inge (Eds.), The new public finance: Responding to global changes (pp. 471-485). New York, NY: Oxford University Press. Jallov, B. (2004). Community radio for empowerment and impact. Journal of Development Communication, 15(2), 56-58. Jankowski, N. (2003). Community media research: A quest for theoretically grounded models. The Public, 10(1), 5-14. King, G. (2017). History of struggle: The global story of community broadcasting practices, or a brief history of community radio. Westminster Papers in Communication and Culture, 12(2), 18-36.

King, G., Albinati, C., Khoo, A., Moores, C., \& Tunsistra-Harris, J. (2016). Groundwire: Growing community news journalism in Canada. In M. Gasher, C. Brin, C., Crowther, G. King, E. Salamon, \& S. Thibault (Eds.), Journalism in crisis: Bridging theory and practice for democratic media strategies in Canada. Toronto, ON: University of Toronto Press.

Leal, S. (2009). Community radio broadcasting in Brazil: Action rationales and public space. The Radio Journal, 7(2), 155-170. 


\section{Bonin-Labelle \& Demers (2019)}

Lévesque, L. (2018). Radios communautaires du Québec et du Canada réunies pour partager leurs défis. URL: https://lactualite.com/actualites/2018/11/06/radios-communautaires-du-quebec-et-du-canada-reunies-pour -partager-leurs-defis/ [March 13, 2019].

Light, E. (2011). From pirates to partners: The legalization of community radio in Uruguay. Canadian Journal of Communication, 36(1), 51-67.

Light, E. (2012). Public participation and community radio in Quebec. In K. Kozolanka, P. Mazepa, \& D. Skinner (Eds), Alternative media in Canada (pp. 145-164). Vancouver, BC: UBC Press.

Local News Research Project. (2019). URL: http://localnewsresearchproject.ca/

Magpanthong, C., \& McDaniel, D. (2011). Media democratization at the crossroads: Community radio in Thailand and Malaysia. Journal of Radio \& Audio Media, 18(1), 116-128.

Meadows, M., \& Foxwell, K. (2011). Community broadcasting and mental health: The role of local radio and television in enhancing emotional and social well-being. Radio Journal: International Studies in Broadcast \& Audio Media, 9(2), 89-106.

Mhiripiri, N. (2011). Zimbabwe's community radio "initiatives": Promoting alternative media in a restrictive legislative environment. Radio Journal: International Studies in Broadcast \& Audio Media, 9(2), 107-126.

Ministry of Training, Colleges and Universities. (2019). Affordability of post-secondary education in Ontario. URL: https: //news.ontario.ca/maesd/en/2019/01/affordability-of-postsecondary-education-in-ontario.html [March 7, 2019].

Murillo, M. (2003). Community radio in Columbia: Civil conflict, popular media and the construction of public sphere. Journal of Radio Studies, 10(1),120-140.

O'Connor, A. (2004). Community radio in Bolivia: The miners' radio stations. Lewiston, NY: Edwin Mellen Press.

O'Connor, M. (2012). The learning and teaching partnership of the community radio and tertiary education sectors at Radio Adelaide, 2SER and 2MCE. 3CMedia: Journal of Community, Citizen's \& Third Sector Media \& Communication, 7, 33-39.

Potts, K., \& Brown, L. (2016). Becoming an anti-oppressive researcher. In M. Webber \& K. Bezanson (Eds.), Critical readings in sociology: Rethinking sociology in the 21st century (pp. 90-109). Toronto, ON: Canadian Scholar's Press.

Rennie, E. (2007). Community media in the prosumer era. 3CMedia: Journal of Community, Citizen's \& Third Sector Media \& Communication, 3, 25-32.

Rennie, E., Berkeley, L., \& Murphet, B. (2010). Community media \& ethical choice. 3CMedia: Journal of Community, Citizen's \& Third Sector Media \& Communication, 6(7), 11-25.

Rodríguez, C., \& El Gazi, J. (2009). The poetics of indigenous radio in Columbia. Media Culture \& Society, 29(3), 449-468.

Salter, L., \& Odartey-Wellington, F.N.L. (2008). The CRTC and broadcasting regulation in Canada. Toronto, ON: Carswell.

Scarone Azzi, M., \& Sánchez, G. (2003). Legislation on community radio broadcasting: Comparative study of the legislation of 13 countries. Paris, FR: UNESCO.

Sharma, A. (2011). Emergence of community radio: Harnessing potential role for rural development. Journal of Development Communication, 22(2), 29-50.

Seneviratne, K. (2011) Community radio via public service broadcasting: The Kothmale model. Journal of Radio \& Audio Media, 18(1),129-138.

Skinner, D. (2012). Sustaining independent and alternative media. In K. Kozolanka, P. Mazepa, \& D. Skinner (Eds.), Alternative media in Canada (pp. 25-45). Vancouver, BC: UBC Press.

Smirès, Y. (2011). Politiques publiques et participation citoyenne des femmes : Impacts des radios communautaires su Sénégal sur les droits économiques et civils. Saarbrücken, DE : Éditions universitaires européennes.

Torres, B.A. (2011) Community radio stations in Brazil. Journal of Radio \& Audio Media, 8(2), 347-357.

Wagg, H. (2004). Empowering youth with radio power: "Anything goes" on CKUT Campus-community radio. Journal of Radio Studies, 11(2), 268-276. 
Welch LLP. (2017). Audit requirements for not-for-profit organizations. URL: http://www.welchllp.com/blog/audit -requirements-for-not-for-profit-organizations/ [February 23, 2017].

Winceck, D. (2010). Financialization and the crisis of the media: The rise and fall of (some) media conglomerates in Canada. Canadian Journal of Communication, 35(3), 365-393.

\section{ABOUT THE AUTHORS / LES AUTEURS}

Geneviève A. Bonin-Labelle is an associate professor in the Department of Communication at the University of Ottawa. Email: gbonin@uottawa.ca.

Jean-Simon Demers is a graduate from the Department of Communication at the University of Ottawa. Email: jsdemrs@gmail.com. 